\title{
A Part as an Object of Assembly
}

\section{Štefan Václav, Peter Pokorný, Adriana Kamenszká}

Institute of Production Technologies, Faculty of Materials Science and Technology in Trnava, Slovak University of Technology, Slovakia

Email: stefan.vaclav@stuba.sk,peter.pokorny@stuba.sk, adriana.kamenszka@stuba.sk

How to cite this paper: Václav, Š., Pokorný, P. and Kamenszká, A. (2021) A Part as an Object of Assembly. World Journal of Engineering and Technology, 9, 904-915. https://doi.org/10.4236/wjet.2021.94062

Received: October 23, 2021

Accepted: November 26, 2021

Published: November 29, 2021

Copyright $\odot 2021$ by author(s) and Scientific Research Publishing Inc. This work is licensed under the Creative Commons Attribution International License (CC BY 4.0).

http://creativecommons.org/licenses/by/4.0/ (c) (i) Open Access

\begin{abstract}
Assembly is currently a very important element in the production process. We can also define it as the last stage in the production process. It greatly affects the quality of the product and especially the time needed to make the final product. The presented article is a contribution to the improvement of methods in the field of technological design of the product in terms of assembly, resp. in the field of methodologies known as DFA, which in its entirety means Design of Assembly. The general objective of improving the assembly process is in most cases reducing the cost of the product. With the gradual development of the technologies coming into practice, companies are focusing mainly on improving the elements of assembled products of the assembly system. This state can be achieved, for example, by reducing the number of components, so the complexity and laboriousness of the assembly will be radically reduced. This in turn leads to a decrease in unit assembly costs. Proper assembly settings can help a company succeed in the competition and thus contribute to a stable position of the company in the market. The aim of the article is to find the other objective indicators of assembly quality evaluation.
\end{abstract}

\section{Keywords}

Design for Assembly, Material Properties, Theory of Orientation

\section{Introduction}

Assembly plays a decisive role in global production in terms of its share in the total costs of the products assembled and in terms of the number of people working in the field.

The author [1] indicates that the percentage of the workers in assembly out of the total number of the workers in manufacturing in the U.S.A. ranged from $26.3 \%$ (bicycles) to $45.6 \%$ (automobiles), while the cost of the product assembly represented typically more than $50 \%$ of the total costs. 
Despite the above-mentioned importance of assembly in the industry, the discontinuous production processes have not been paid adequate attention until recently. It was sufficient to manufacture parts and then an operative reasonably and inexpensively assembled each product manually.

Total automation of the assembly is often not feasible for economic and also social reasons. There will always be individuals seeking to perform manual jobs and humanized and mechanized assembly will always provide job opportunities for them.

\section{A Part as an Object of Assembly}

This chapter will define the material properties of the components, and discuss the shape, theory of orientation of the parts as well the calculation of laboriousness of the parts.

\subsection{Material Properties of a Part}

The material of a part has a decisive impact on the complexity and laboriousness of assembly. Examples of the parts manufactured of various materials are listed in Figure 1.

\begin{tabular}{|c|c|c|c|}
\hline & Material & Example & Efect on assembly \\
\hline 1 & Solid & & $\begin{array}{c}\text { Problem only } \\
\text { with orientation }\end{array}$ \\
\hline \multirow{3}{*}{2} & Brittle & & $\begin{array}{c}\text { Smashing in materials } \\
\text { handling }\end{array}$ \\
\hline & Abrasive & & $\begin{array}{l}\text { Abradability in } \\
\text { materials handling }\end{array}$ \\
\hline & Flexible & & $\begin{array}{l}\text { Indeterminableness } \\
\text { in assembly }\end{array}$ \\
\hline \multirow{4}{*}{3} & Gaseous & & to ration only \\
\hline & Liquid & & to ration only \\
\hline & Gelly & & to ration only \\
\hline & Loose & & to ration only \\
\hline
\end{tabular}

Figure 1. Part as an object of assembly. Classification of material properties of parts: $1-$ Solids; $2-$ Brittle, abrasive, and flexible materials; $3-$ Gaseous, liquid, gels, and loose materials [2]. 
In terms of assembly, the important are the features of the components related to the handling. The solid, fragile, or flexible components are handled in different ways.

The free-form components in liquid, pasty, granular or powdery states represent a special group. Their positive feature in terms of assembly is that their assembly handling is simple. The materials are just fed into the assembly cavity.

After filling the cavity, the material solidifies, forming a solid component which fills any cavity, regardless of its size and tolerance. The example includes the mounting of semi-conductor elements in epoxy resins in electronics or sealing the glass into the frames of headlights. A special feature of this procedure is that the component is "produced" during assembly, while eliminating the issue of orientation. This includes adhesives, which, after solidification, form a "bonding element" just like a solder and other binders.

The adhesives also have remarkable features, such as locking (in screw bonds), insulation or conducting elements (bonding copper wires with carbon brushes for electric motors) [3].

Very progressive are multi-material parts made of different materials in different situations. The composite materials are also common in engineering. Varying the structure and density of the filling material (e.g. carbon fiber) in epoxy resins, a light aircraft or a robotic arm can be manufactured with varying strength in different places [4] [5].

The revolution in electrical engineering and assembly in terms of miniaturisation was the discovery of the semiconductor effect and its subsequent use in the development of new electronic devices (diode, transistor, photodiode, a semiconductor laser) and circuits (integrated circuits, ICs). The semiconductor effect can be achieved by adding miniature amounts of the dotant (e.g. phosphorus) to the base material (e.g. silicon).

The task of "how to invent an invention" is the subject of general methods of creativity, e.g. TRIZ method (from Russian: teoriya resheniya izobretatelskikh zadatch, equivalent of the English acronym TIPS "the theory of inventive problem solving") [6] [7]. The invention may have originated by applying Value Engineering. No single method is enough if the investigator does not possess superior knowledge in the given field (e.g. the invention of laser and the "semiconductor effect").

The invention of a new technology (e.g. printed circuit boards, multi-material component) may also have a major impact on the assembly.

DFA methods can be applied only for the inventions "of the second order" (the principle remains, but a better arrangement is preferred), since they entered the scene, when competitors had already switched to more favourable inventions [8].

In terms of assembly, products can be divided into three basic groups:

Group 1: Solid (incl. composite) products;

Group 2: Products with flexible surface; 
Group 3: Free-form products (Figure 1).

A product made of flexible parts is for example a wiring harness in the passenger cars. The flexibility of cables and undefined shape of the product nearly eliminates the automation of the assembly. The solution to this problem may be to find a new invention enabling the transfer of energy from the battery and signals from the panel in other than a wired manner.

Other examples are the conductors that are difficult to be handled and oriented by a machine. There is a trend to replace them with solid components (PCB, WIRE WRAP technology, sandwich construction, etc.).

The brittle and abrasive components cannot be garbled or vibration-oriented (e.g. light bulbs), as this impedes the possibility of easy and inexpensive automation.

The scope of this article will allow us to focus only on the most commonly used components in engineering, which are made of metal or plastic materials with satisfactory toughness and low brittleness.

The most frequently used in mechanical engineering are rigid parts (Figure 1, group 1), which do not require special treatment (orientation and handling) in the common assembly machines. An unfavourable feature is the specific shape of each component, which poses problems with grasping and orientation in particular [9].

\subsection{Shape of a Part and Orientation}

Let us first define shape, orientation and symmetry.

The shape is a unique spatial arrangement of neighbouring areas separating the material of the body from the environment.

The areas can be defined mathematically (cylinder, cone, polynomial cam surface). Such surfaces smoothly interlock (having common curves) or intersect at the intersection's areas.

In exceptional cases, the shape is a single mathematical surface (sphere, ellipsoid, i.e. mathematically defined shapes). There are also shapes mathematically undefined, with unknown boundaries of areas (for example, a bust of a human head).

The technical surfaces and shapes defined mathematically will be discussed further.

The orientation in the most complex cases is the sequential or simultaneous rotation of the body around the axes $x, y, z$, until the body in the system of the axes $x, y, z$ is oriented from the random to the desired angular position.

The shape of the body determines if all three rotations are to be performed or if the rotation around each of the axes must be a full revolution.

The common definitions of symmetry [10] differ in detail, but they agree that planar shapes may be symmetrical with respect to the straight line, and spatial ones with respect to the plane, while the line and the plane represent the "mirror symmetry". 
The symmetry in geometry is a property of shape, where each point A of the body surface on one side of the symmetry plane has its associated point $A^{*}$ lying on the perpendicular line on the opposite side of the symmetry plane. This is at an equal distance from the plane of symmetry as point A (Figure 2(a)). The definition also applies to space. In space, plane is the "mirror symmetry".

The prism is symmetrical with respect to the planes $\rho_{1}, \rho_{2}, \rho_{3}$ (Figure 2(c)), the cylinder with respect to the volume of planes intersecting the axis of symmetry $\mathrm{o}_{1}$ (Figure $2(\mathrm{~d})$ ), the ball has three such axes $\mathrm{o}_{1}, \mathrm{o}_{2}, \mathrm{o}_{3}$ (Figure 2).

The symmetry with respect to the axis means that, for a given body, there is an infinitely large volume of symmetry planes passing through the axis of symmetry.

The symmetry with respect to the point means that there are infinitely many axes of symmetry passing through that point.

According to various encyclopaedia and dictionaries, the word symmetry has different meanings in cosmology, biology, medicine, etc. If the body is symmetrical with respect to the horizontal plane in any orientation, two positions are acceptable: the upper side or the lower side of the body is above the plane of symmetry.

The symmetry reduces the number and size of standard movements. Apart from symmetry, important for assembly are the various relationships between the contour width, thickness and length of the body - slenderness ratios, affecting the percentage of the components falling on a plane and placed on the surface $X$, surface $Y$, and surface $Z$, etc.

We are interested in the parts that, after falling, are placed on the surface where they will be assembled in a product (without necessity of being oriented). We are interested in increasing their number [9].

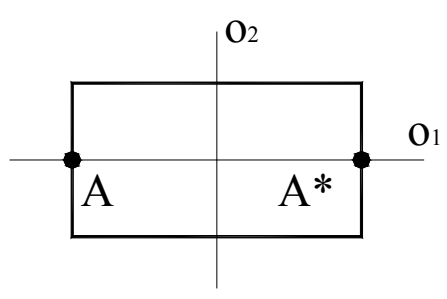

a

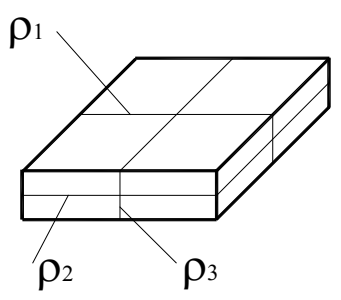

c

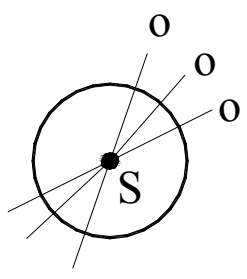

$\mathrm{b}$

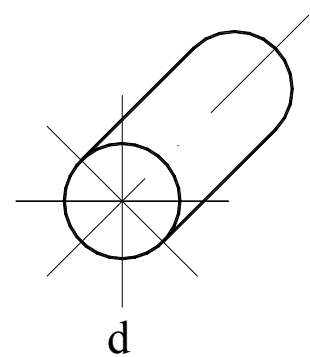

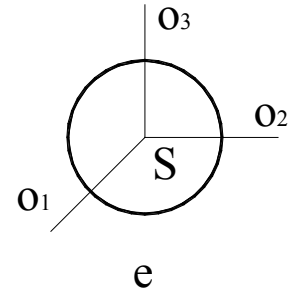

e

Figure 2. Part as an object of assembly. Symmetry-basic concepts: (a) Rectangle; (b) Circle; (c) Prism; (d) Cylinder; (e) Sphere. 


\subsection{Theory of Orientation}

Unfortunately, the parts from the production are usually supplied for assembly in a disordered and disoriented state. This is the reason why the research papers study the orientation of components mainly deal with automatic orientation [11] [12] [13].

The first theoretical contributions focused on explanation the shape classifiers and sample solutions of automatic orientation and reported a catalogue of successful solutions [14] [15]. Only some of the papers have tried to arrange the parts according to the degree of symmetry.

Along with the shape and size of components assembled, the orientation [16] is crucial for the performance and assembly costs. Professor Boothroyd was the first researcher to deal with the issue of the component's orientation and the systemisation of the procedure [12].

Boothroyd [13] [17] concentrated only on the orientation of slender parts of a cylindrical shape. He found the prevalence of two types of symmetry, or asymmetry, so called " $\alpha$ symmetry" and " $\beta$ symmetry" (imbalance) (Figure 3 ). These values are considered as a criterion of assembly complexity.

Alpha Symmetry - the symmetry plane perpendicular to the longitudinal axis of the part.

Beta Symmetry-the symmetry with respect to rotation of the part around the longitudinal axis.

Later, he quantified the " $\alpha$ and $\beta$ symmetries" [12] with respect to the required rotation angles in degrees (Figure 4).

The cylinder in Figure 3 is " $\alpha$ and $\beta$ symmetric" and can be nested to the opening by its upper or lower side. When orientating a cylindrical part which has been nested from one side, it is already " $\alpha$ asymmetric" and can be inserted into the opening only by one side. Similarly other displayed components were assessed; however, the last oriented component could not be measured by the author.

In his work, Boothroyd stated that it was only the beginning of this theory, as it does not apply to the components which are not axially symmetric, but are quite general in form.
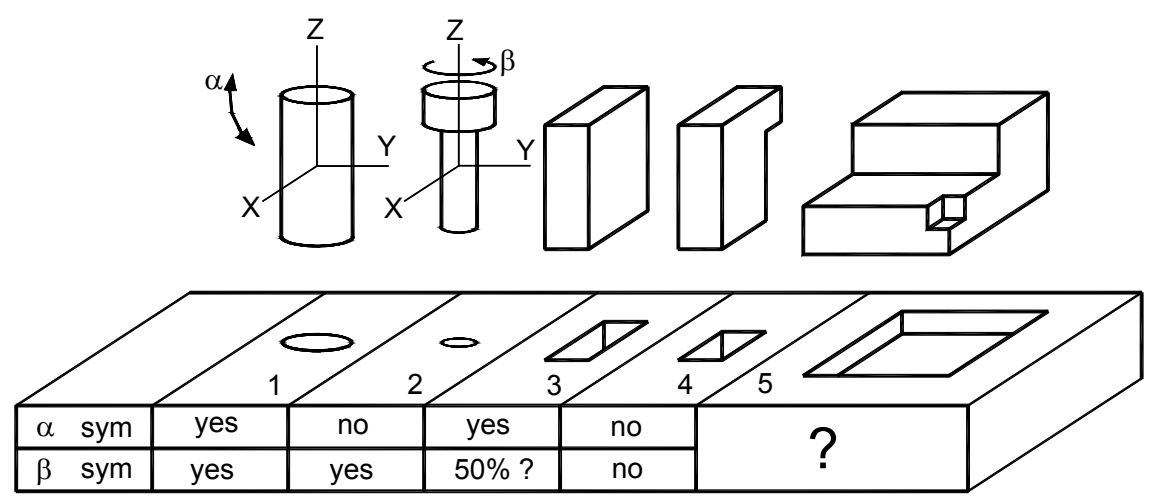

Figure 3. Boothroyd theory of orientation [1]. 


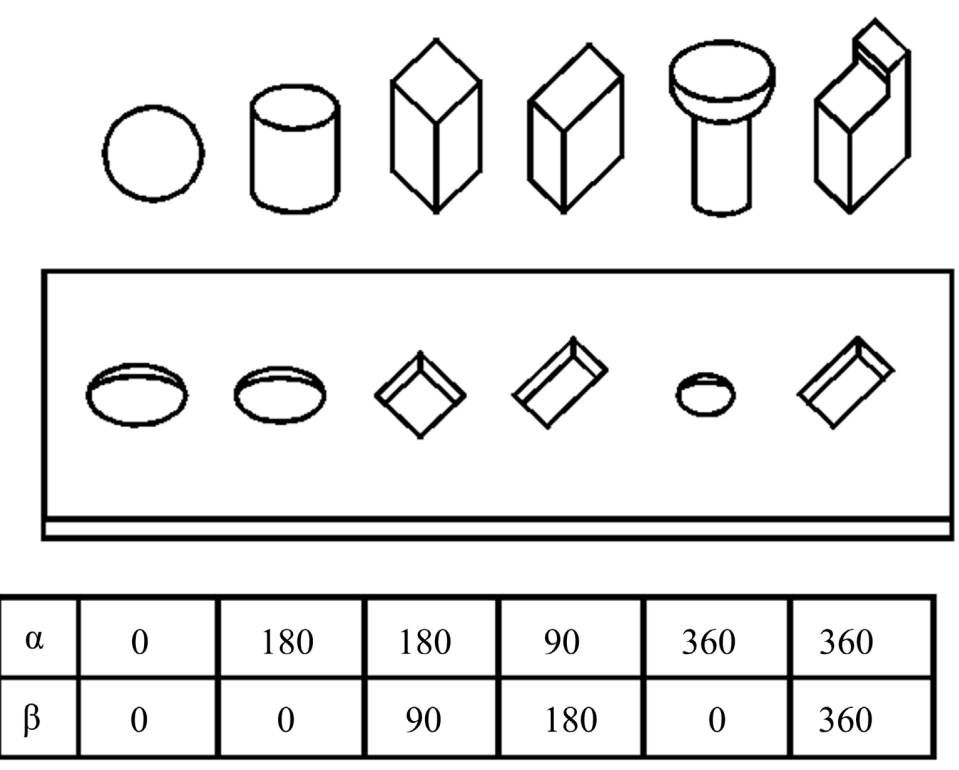

Figure 4. Component as an object of assembly [1].

Before the assessment, Boothroyd pre-oriented the component so that its longitudinal axis was in the direction of axis " $\mathrm{z}$ " (Figure 3). The component was thus rotated by "gamma symmetry"; however, its value was not assessed.

Valentovič focused on the above-mentioned theory by resolving the orientation of components that are not axially symmetric, i.e. he solved the orientation theory of components of any shape.

Valentovič [18] [19] found that, regarding the three-dimensionality of space, three symmetries should be distinguished for each shape (whether it is slender or not). Each of them can be measured by the number of revolutions (or fractions of a revolution).

He developed a theory applicable on all possible shapes of parts. Let us illustrate it first on the "flat" components (Figure 5(a)). As can be seen, e.g. a circle does not have to be oriented into a circular hole; it can simply be put into the hole [9].

If it is necessary to insert a square into a square hole, in the worst case a quarter revolution can be taken; if it is necessary to insert a hexagon into a regular hexagonal hole, in the worst case, a sixth of a revolution can be taken. If the shape is quite general, the full revolution is needed in the worst case.

The author of the theory developed the principle for all three views and concluded that to assess the complexity and laboriousness of orientation, it was necessary to carry out the operation three times: in a draft view, side view and plan view of the part (Figure 5(b)). The orientation of a sphere in all three views does not need any revolutions, which means that laboriousness is equal to zero. However, when orienting a cylinder (Figure 5(b)), 1/2 a revolution in the draft view is needed, $1 / 2$ a revolution in the side view and 0 revolutions in the plan view. When orienting a cylinder embedded from one side, 1 full revolution in the draft view is needed, 1 full revolution in the side view and 0 revolutions in 

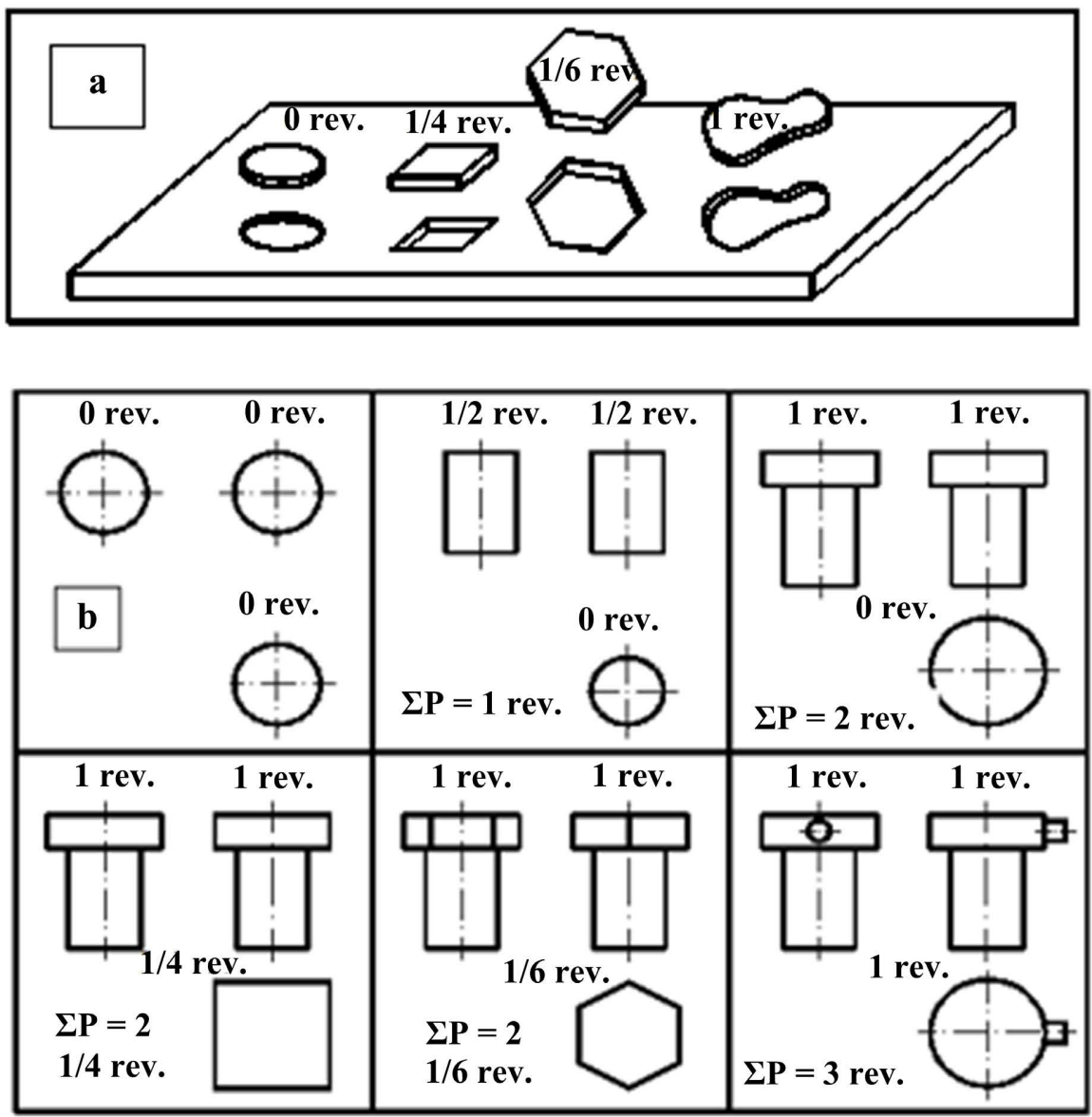

\begin{tabular}{|l|c|c|}
\hline & & \\
\hline $\mathrm{c} \quad P_{\mathrm{o}}=1 / 2 \mathrm{rev}$. & $P_{0}=1 / 6 \mathrm{rev}$. & $P_{0}=1 \mathrm{rev}$. \\
\hline $\mathrm{d} \quad \mathrm{P}_{\mathrm{s}}=\frac{2 \pi \mathrm{r}}{2}$ & $P_{\mathrm{s}}=\frac{2 \pi \mathrm{r}}{6}$ & $P_{\mathrm{s}}=\frac{2 \pi \mathrm{r}}{1}$ \\
\hline
\end{tabular}

Figure 5. Laboriousness of orientation and assembly: (a) Orientation in plane measured in revolutions; (b) Orientation in space measured in revolutions $\left(P_{o}\right)$; (c) and (d) Laboriousness of orientation $\left(P_{o}\right)$ and trajectory laboriousness $\left(P_{s}\right)$.

the plan view. The figure similarly explains the orientation of other shapes, even the most complex ones. To orientate the latter components, 1 revolution was needed in draft view, 1 revolution inside view and 1 revolution in plan view.

The above-mentioned theories of orientation consider both big and small parts, and yet the size makes the difference.

It is therefore recommended that the given laboriousness is not calculated only by using rotations $\left(P_{o}\right)$, but also considering the rotary trajectories to be carried out $\left(P_{s}\right)$. When turning a large part, trajectories are greater than when turning a small component. 
The above-mentioned indicates that the laboriousness of orientation $\left(P_{o}\right)$ is the sum of the orientation trajectories of the draft view, side view and plan view as shown in Figure 5(c). This means that according to Valentovič, laboriousness of rotating a rectangle is $1 / 2$ a turn. The author recommends that the laboriousness means a semi-circle (Figure 5(d)), i.e. it is a path described by a semi-circle. The same applies for other shapes. In this way, the sum of the pathways determines the laboriousness of the given component orientations.

Figure 5(d) shows how to consider both the orientation and handling dimensions of a component when investigating laboriousness (trajectory laboriousness of orientation $-P_{s}$ ).

\subsection{Calculation of Laboriousness of Assembly}

Because during a deep study of the literature it was not possible to find more relevant information, this encouraged the authors to process this issue not only in terms of theory, but also in terms of practice, which will be described below.

Figure 6 illustrates a practical example of the above-mentioned theory: the prism is fastened in a clamp, there is a screw to be screwed into the top of the prism, and a pin to be inserted at the side.

To calculate the laboriousness of the whole orientation, examined will be the laboriousness of all orientation movements (all movements in terms of orientation) performed within the process of assembly.

First, the prism is to be oriented (Figure 6, position 1) by $1 / 4$ of a revolution before being inserted into the clamp. Closely above the opening, the screw must be oriented (Figure 6, position 2); orientation can be calculated as described above (2 1/6 revolution). The future product must be then turned by 90 degrees, in order to insert the pin from the top, and then the orientation necessary for the pin 1 revolution, (Figure 6, position 3) can be calculated again.

From the process of calculating the orientation, it is easy to derive:

Trajectory laboriousness $P_{s}$ :

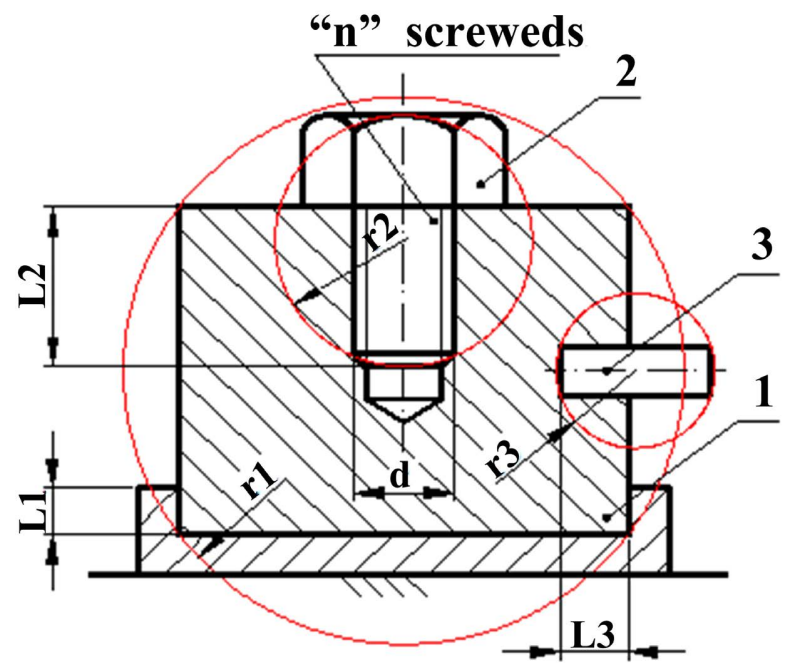

Figure 6. Laboriousness of assembly [20]. 1-Prism; 2-Screw; 3-Pin. 
- Prism $\left(\frac{1}{4} 2 \pi r_{1}+\frac{1}{4} 2 \pi r_{1}+\frac{1}{4} 2 \pi r_{1}\right)$;

- Screw $\left(2 \pi r_{2}+2 \pi r_{2}+\frac{1}{6} 2 \pi r_{2}\right)$;

- $\operatorname{Pin}\left(\frac{1}{2} 2 \pi r_{3}+\frac{1}{2} 2 \pi r_{3}+0\right)$.

Assembly laboriousness $\boldsymbol{P}_{\boldsymbol{m}}$ :

- Prism: L1 (clamping);

- Screw: $L_{2}+\pi d n$ (screwing or feed and rotation);

- Turning the hole for the pin into the vertical position: $\frac{1}{4} 2 \pi r_{1}$;

- Pin: L3.

Total trajectory assembly laboriousness $P_{c s}$ :

$$
P_{c s}=P_{s}+P_{m} \quad[\mathrm{~mm}]
$$

where:

$P_{c s}=$ total trajectory and assembly laboriousness $[\mathrm{mm}]$,

$P_{s}=$ trajectory laboriousness $[\mathrm{mm}]$,

$P_{m}=$ assembly laboriousness $[\mathrm{mm}]$.

\section{Conclusions}

The above-mentioned suggests that the orientation is a phenomenon typical for assembly and represents up to $50 \%$ of the amount of work performed in the process of assembly. It is because the parts are generally supplied for assembly in a disoriented position.

When designing a product, it is not necessary to add partial laboriousness; it is enough just to minimize those variables that increase the overall laboriousness.

Rules:

1) The shorter the trajectory laboriousness, the better the product design.

2) The total trajectory and assembly laboriousness can be decreased by choosing suitable forms and dimensions.

Figure 6 presented in the article shows a practical example from practice. Further planned research by the authors will deal with the extension of the described method to evaluate the complexity and laboriousness of the entire assembly process.

\section{Acknowledgements}

The contribution is sponsored by the project VEGA 1/0019/20: Accurate calculations, modelling and simulation of new surfaces based on physical causes of machined surfaces and additive technology surfaces in machinery and robotically machining conditions.

\section{Conflicts of Interest}

The authors declare no conflicts of interest regarding the publication of this paper. 


\section{References}

[1] Boothroyd, G. (1991) Assembly Automation and Product Design. 2nd Edition, Taylor \& Francis Group, Boca Raton.

[2] Václav, Š. (2005) Objektívna Metóda pre Montáž. Ph.D. Thesis, Slovak University of Technology, Trnava.

[3] Kellar, E.J.C. (2021) Joining Similar and Dissimilar Materials. In: Adams, R.D., Ed., Woodhead Publishing Series in Welding and Other Joining Technologies, Adhesive Bonding, 2nd Edition, Woodhead Publishing, Sawston, 385-405. https://doi.org/10.1016/B978-0-12-819954-1.00004-6

[4] Vazquez-Martinez, J.M., Del Sol, I., Salguero, J., Batista, M. and Alcalá, R. (2021) Mechanical Joining of Composites: Drilling Related Aspects. In: Brabazon, D., Ed., Encyclopedia of Materials. Composites, Elsevier, Amsterdam, 420-436. https://doi.org/10.1016/B978-0-12-819724-0.00066-5

[5] Domnina, K. and Pivarciova, E. (2021) Multifactorial Approach for Obtaining Cellular Composite Materials. Amos Ostrava, Ostrava.

[6] Ekmekci, I. and Nebati, E.E. (2019) Triz Methodology and Applications. Procedia Comouter Science, 158, 303-315. https://doi.org/10.1016/j.procs.2019.09.056

[7] Sheu, D.D., Chiu, M. C.H. and Cayard, D. (2020) The 7 Pillars of TRIZ Philosophies. Computers \& Industrial Engineering, 146, Article ID: 106572. https://doi.org/10.1016/j.cie.2020.106572

[8] Melckenbeeck, I., Burggraeve, S., Doninck, B., Vancraen, J. and Rosich, A. (2020) Optimal Assembly Sequence Based on Design for Assembly (DFA) Rules. Procedia CIRP, 91, 646-652. https://doi.org/10.1016/j.procir.2020.02.223

[9] Václav, Š. (2012) Vybrané State z Teórie Montáže. Habilitation thesis, Slovak University of Technology, Trnava.

[10] Petráčková V. and Kraus J. (1997) Slovník cudzích slov. Slovenské Pedagogické Nakladatel'stvo, Bratislava.

[11] Baessler, R. and Schmaus, T. (1988) Procedure of Assembly-Oriented Product Design. Proceedings of the 2nd International Conference on Product Designed for Manufacture and Assembly, London, March 1988, 32-33.

[12] Boothroyd, G., Dewhurst, P. and Knight. W.A. (2010) Product Design for Manufacture and Assembly. 3rd Edition, CRC Press, Boca Raton. https://doi.org/10.1201/9781420089288

[13] Boothroyd, G., Poli, C. and Murch, L.E. (1982) Automatic Assembly. Marcel Dekker Inc., New York.

[14] Łunarski, J. (1991) Technologiczność konstrukcji maszyn montowanych automatycznie. Tekoma, Warsaw.

[15] Johansson, M. (1989) Product Design and Materials Handling in Mixed-Model Assembly. Ph.D. Thesis, Chalmers University of Technology, Göteborg.

[16] Senderská, K. (2007) Automatická orientácia a prívod súčiastok v automatizovanej montáži.

https://www.sjf.tuke.sk/transferinovacii/pages/archiv/transfer/10-2007/pdf/69-74.pdf

[17] Boothroyd, G. and Redford, A.H. (1968) Mechanized Assembly; Fundamentals of Parts Feeding, Orientation, and Mechanized Assembly. 1st Edition, McGraw Hill, New York.

[18] Valentovič, E. (2000) Geometric and Static Conditions of Assembly. Assembly Au- 
tomation, 20, 233-237. https://doi.org/10.1108/01445150010372179

[19] Valentovič, E. (1996) Knowing Your Orientation. Assembly Automation, 16, 31-33. https://doi.org/10.1108/01445159610117681

[20] Václav, Š. (2013) Theoretical Aspect of Assembly. 1st Edition, Hochschule Anhalt, Köthen. 